\title{
Effect of climate variables on the modeling of vegetation net primary productivity in karst areas
}

\author{
B. Wang $^{\text {a,b }}$, S. Yang ${ }^{b}$ and Y. Chen ${ }^{c}$ \\ ${ }^{a}$ Forestry College, Inner Mongolia Agricultural University, Hohhot 010019, China \\ ${ }^{b}$ School of Geography, Beijing Normal University, Beijing 100875, China \\ ${ }^{c}$ CSIRO Land and Water, Canberra ACT 2601, Australia \\ Email: wbingbing2008@,126.com
}

\begin{abstract}
Green plants play an important role in matter and energy transformations and are key messengers in the carbon and energy cycle. Vegetation net primary productivity (NPP) reflects the capability of plants to convert solar energy into photosynthate (fixed carbon). It can be used as a direct indicator of current status and future trend of ecological processes affected by human activities and climate variability, especially in fragile ecological environments such as karst areas where rock-desertification increasingly occurs.
\end{abstract}

Using remote sensing and geographic information system technologies, research on spatio-temporal variations of NPP and its response to changes in climate variables (temperature, rainfall and solar radiation) in Guizhou province of China was conducted. Karst areas within the study area were delineated to explore the relationship between NPP and climate variables. The NPP model developed by Wang et al. (2010) was used. This model is a modification of the light use efficiency (LUE) model of Running et al. (2000), validated for this region in China. As input to the model, three climate scenarios were designed - one representing current conditions and two for hypothetical future conditions. Both future scenarios have a $2^{\circ} \mathrm{C}$ increase in temperature and $6 \%$ increase in rainfall, applied spatially across the region using a constant scaling factor on the current condition scenario. The first future scenario has unchanged solar radiation; and the second has a $10 \%$ increase in solar radiation for investigating the effect of solar radiation on NPP.

The model was run on a monthly time step for one year. Under the current condition scenario, the spatiotemporal patterns of monthly NPP were analysed using MODIS imagery, with the climate variables as model inputs. The relationships between NPP and temperature, and NPP and rainfall, were quantified using single and partial correlation. The hypothetical future condition scenarios were then used to explore the response of NPP to changes in these variables.

This paper reports on the results of this modelling under all scenarios, with particular interest in the relationship between solar radiation and karst areas. Model results show that, under the current condition scenario, the mean annual NPP of terrestrial vegetation is $421 \mathrm{gCm}^{-2}$ with the NPP in karst areas being $11.9 \%$ lower than in non-karst areas. Maximum and minimum NPP values occur in July and January, respectively. The results show strong correlations between NPP and climatic variables: (1) Temperature is a key factor which significantly limits vegetation growth in the northwest. The correlation between NPP and temperature decreases from north to south, and is stronger in karst (than non-karst) areas. (2) The correlation between NPP and rainfall is most significant in the southeast and west in comparison with other areas, and is lower in karst (than non-karst) areas. Under the first future scenario, the total annual NPP decreases from $74 \times 10^{6} \mathrm{tC}$ to $73 \times 10^{6} \mathrm{tC}$; whereas under the second future scenario, annual NPP increases from $74 \times 10^{6} \mathrm{tC}$ to $79 \times 10^{6} \mathrm{tC}$. The results from both future scenarios indicate that the largest variation in NPP occurs in karst areas with severe rock-desertification, indicating solar radiation is a dominant factor affecting NPP in karst areas.

There are obvious regional differences on spatio-temporal patterns of NPP between karst areas and non-karst areas. The analysis of the interactions among three climate variables - temperature, rainfall and solar radiation has contributed to our understanding of their contributions to NPP, especially in karst areas.

Keywords: Modeling, Net Primary Productivity (NPP), climate variables, remote sensing, karst areas 


\section{INTRODUCTION}

Green plants play an important role in matter and energy transformations and are key messengers in carbon and energy cycle. Vegetation net primary productivity (NPP), the amount of carbon fixed by plants, is a fundamental integrating process in all ecosystems (McNaughton et al., 1989). Terrestrial NPP has been an important component of ecological studies since the 1960s. For example, in 1964, the International Biological Program (IBP) under the United Nations Educational, Scientific and Cultural Organization (UNESCO) made a series of large-scale measurements and produced a census of primary biomass production (Newbold, 1967). NPP has not only served as a compelling indicator of earth surface system health (Running et al., 2000); it has also played a crucial role in the terrestrial carbon cycle (Field et al., 1998; Keeling et al., 1996). Therefore, NPP and its response to changes in climate (whether under climate change or climate variability) has been a focus of global change research (Cramer et al., 1999). Many of the earlier studies used historical data sets (Cao et al., 2003; Fang et al., 2003; Melillo et al., 1993; Nemani et al., 2003). More recently, remote sensing has emerged as an advanced technology for monitoring vegetation dynamics, with numerous efforts made to incorporate remotely sensed data into NPP models and to estimate global NPP (Cao et al., 2003; Fang et al., 2003; Goetz and Prince, 1996; Prasad et al., 2006; Seaquist et al., 2003). While these studies are geographically diverse, none explicitly address landscapes that include karst.

'Karst' refers to a type of terrain, usually formed on carbonate rock where groundwater has solutionally enlarged openings to form a subsurface drainage system. The Guizhou province in China is a 'Karst Province', where rock-desertification is becoming increasingly severe together with the 'karst-poverty' phenomenon. Because of these issues, there is an urgent need to investigate terrestrial material and energy cycles for sustainable regional development in karst areas. This paper explores the usefulness of NPP, particularly its ability to reflect the effect of changes in climate variables, as a suitable measure for this purpose. Therefore, the aim of this study is to derive the spatio-temporal patterns of monthly NPP in Guizhou province, and to explore the effect of climate variables on NPP under different scenarios.

\section{DATA AND METHOD}

\subsection{Study area}

Guizhou province covers $176,167 \mathrm{~km}^{2}$. It is located in the centre of the southwestern karst areas of China (Figure 1a). The karst areas account for $85 \%$ of the total area. The province is characterized by a mild wet climate with annual mean temperature of $15^{\circ} \mathrm{C}$ and annual mean rainfall of $1200 \mathrm{~mm}$ (Xiong et al., 2002).

Based on previous research (Wang et al., 2010), 12 counties were defined as non-karst areas (Figure 1a), being counties with less than $40 \%$ karst area and mostly dominated by forest (Figure $1 \mathrm{~b}$ ). The remaining counties were classified as the karst areas. The differences in NPP between karst and non-karst areas were studied in this paper.

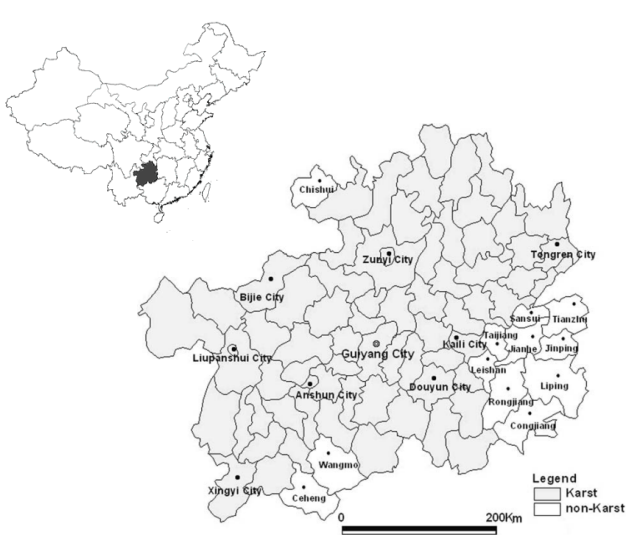

Figure 1a. Distribution of karst areas.

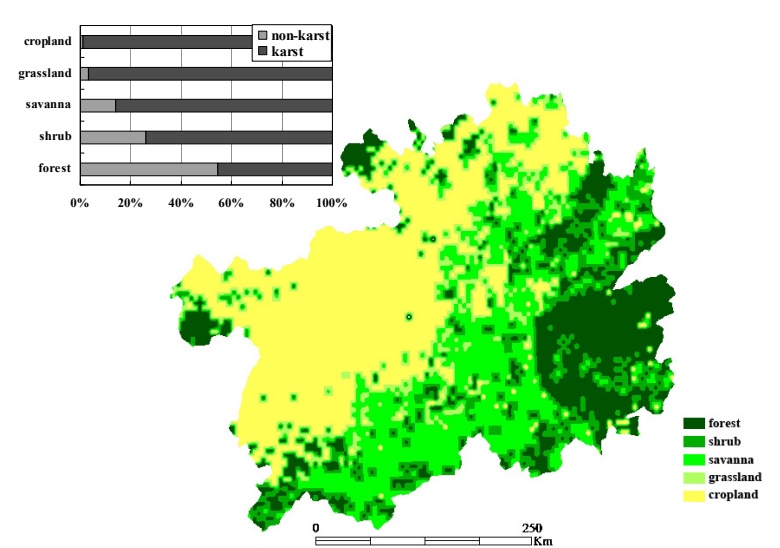

Figure 1b. MODIS land cover classification map.

\subsection{Data source}

In this study, all data were resampled to $1 \mathrm{~km}$ spatial resolution (being the resolution of the underlying remote sensing data) and projected to Albers Conical Equal-Area using ENVI and ArcGIS software.

\section{Remote sensing data}


Moderate Resolution Imaging Spectroradiometer (MODIS) products for 2001 were used. The images were distributed by the EROS Data Center. The products included fraction of photosynthetically active radiation (FPAR), vegetation index, land cover type and red and near-infrared reflectance.

\section{Climate data}

Climate data were provided by the China Meteorological Administration and included rainfall, mean temperature, vapor pressure, relative sunshine duration, relative humidity and wind speed. The climate data layers were interpolated based on observed records (Wang et al., 2010). Data layers for the variables in the future climate scenarios (temperature, rainfall and solar radiation) were derived by using constant scaling factors $\left(2{ }^{\circ} \mathrm{C}\right.$ for temperature, $6 \%$ for rainfall and $10 \%$ for solar radiation) to the current climate data layers.

\section{Other geographic data}

Basic geographic data layers were used, including a DEM, and boundary, terrain and vegetation $(1: 4,000,000)$ maps for Guizhou province.

\subsection{Scenario design}

Based on earlier research results (Wen et al., 1997), three scenarios were designed for studying the spatiotemporal dynamics of NPP and its response to climate variables - one for current conditions and two for future conditions. The future scenarios are totally hypothetical, and assume no change in vegetation. Both have a $2{ }^{\circ} \mathrm{C}$ increase in temperature and a $6 \%$ increase in rainfall on the current conditions. The first scenario has no change in solar radiation (from current) and the second has a $10 \%$ increase in solar radiation, for the purpose of exploring the effect of solar radiation on NPP.

\subsection{Modeling}

Net primary productivity (NPP) is defined as the balance between the total amount of carbon assimilated by photosynthesis and the carbon consumed during plants' respiration (Gao and Liu, 2008). The NPP can be divided into two parts: gross primary productivity and respiration (Equation 1)

$$
N P P=G P P-R_{d}
$$

where NPP $\left(\mathrm{gCm}^{-2}\right)$ is net primary productivity, $\mathrm{GPP}\left(\mathrm{gCm}^{-2}\right)$ is gross primary productivity and $\mathrm{R}_{\mathrm{d}}\left(\mathrm{gCm}^{-2}\right)$ is respiratory consumption (Wang et al., 2010).

GPP is calculated by the LUE model (Running et al., 2000) and requires irradiation, temperature and moisture as inputs (Equation 2)

$$
G P P=\varepsilon_{g} \times F P A R \times Q_{P A R} \times f_{1}(T) \times f_{2}(\beta)
$$

where $\varepsilon_{\mathrm{g}}$ is light use efficiency which is a constant of $2.76 \mathrm{gC} / \mathrm{MJ}$ (Gao and Liu, 2003); $\mathrm{Q}_{\mathrm{PAR}}$ is incident photosynthetically active radiation $\left(\mathrm{MJm}^{-2}\right)$ which requires DEM, vapor pressure and relative sunshine duration as inputs; FPAR is the fraction of photosynthetically active radiation (PAR) absorbed by vegetation using the MODIS/FPAR data directly; $\mathrm{T}$ is temperature $\left({ }^{\circ} \mathrm{C}\right), \mathrm{f}_{1}(\mathrm{~T})$ is the influence of temperature on photosynthesis (Sun and Zhu, 2001); $\beta$ is evaporation ratio, and $f_{2}(\beta)$ is the influence of moisture on photosynthesis which requires DEM, reflectance, rainfall, temperature, vapor pressure, relative sunshine duration, wind speed and relative humidity as inputs (Wang et al., 2010).

The model used in this work has been validated to be suitable for NPP monitoring in Guizhou province (Wang et al., 2010).

\subsection{Statistical method}

In order to study correlations between NPP and climate variables, single correlation (R) and partial correlation (PR) models were employed. $\mathrm{R}$ has been widely applied in many studies, so PR is discussed mainly in this paper.

Partial correlation can determine what the correlation between any two of the variables would be if the third variable was removed (held constant) (Lowry, 2007). It can remove other factors' influences in a complex, interactive system. For example, given that rainfall is fixed, the partial correlation coefficient (PR) of NPP and temperature can be calculated using Equation 3:

$$
\left.P R_{N T, R}=\left(r_{N T}-r_{N R} r_{T R}\right) / \sqrt{\left(1-r_{N R}^{2}\right)\left(1-r_{T R}^{2}\right.}\right)
$$


where $\mathrm{N}, \mathrm{T}$ and $\mathrm{R}$ represent NPP, temperature and rainfall, respectively; $\mathrm{r}_{\mathrm{NT}}, \mathrm{r}_{\mathrm{NR}}$ and $\mathrm{r}_{\mathrm{TR}}$ are the single correlation coefficients of NPP and temperature, NPP and rainfall, and temperature and rainfall, respectively.

\section{RESULTS AND DISCUSSIONS}

In this section, we report on the results of the NPP modelling. The first three subsections report on the spatiotemporal variations in monthly NPP and its correlations with climate variables, under the current condition scenario. $\S 4$ and $\S 5$ use these relationships as the basis for reporting on the effect on NPP of changing climate variables (temperature, rainfall and solar radiation) under the two hypothetical future scenarios.

\subsection{Spatial distribution of NPP under the current condition scenario}

The calculated mean annual NPP in Guizhou province is $421 \mathrm{gCm}^{-2}$. This equates to an annual production from photosynthetic activity of $74 \times 10^{6} \mathrm{tC}$, which is about $3 \%$ of the total NPP in China.

There are very clear spatial patterns in NPP distribution over the study area (Figure 2a). NPP values decrease from the southeast to the west. Most areas in the south/southeast are covered by subtropical evergreen broadleaf, needle leaf and savanna and show high biomass production with an annual NPP value of 400$600 \mathrm{gCm}^{-2}$. The central areas have a lower annual NPP value of $200-450 \mathrm{gCm}^{-2}$. This pattern is driven by severe rock-desertification, land cover and land use. The western areas are characterized by highest altitude, lowest temperature and less rainfall (than other parts of the province), all of which restrict the growth of vegetation. In these western areas, annual NPP values are generally below $400 \mathrm{gCm}^{-2}$, and the lowest annual value of $200 \mathrm{gCm}^{-2}$ occurs in this region.

Annual NPP values in karst areas are generally lower than in non-karst areas. The annual values in karst areas are mostly below $450 \mathrm{gCm}^{-2}$ with a mean of $407 \mathrm{gCm}^{-2}$, while those in non-karst areas range from 400 $600 \mathrm{gCm}^{-2}$ with a mean of $462 \mathrm{gCm}^{-2}$, which is about $13 \%$ higher than that of karst areas.

\subsection{Temporal (monthly) variation of NPP under the current condition scenario}

Under current condition, the maximum NPP values for both karst and non-karst areas occur in July (Figure 2b) when vegetation grows vigorously. The maximum value is $71 \mathrm{gCm}^{-2} \mathrm{month}^{-1}$ for karst areas, which is $8 \%$ greater than for non-karst areas. The minimum values of $12 \mathrm{gCm}^{-2} \mathrm{month}^{-1}$ and $17 \mathrm{gCm}^{-2} \mathrm{month}^{-1}$ for karst and non-karst areas, respectively, occur in January when the temperature is lowest and vegetation growth is limited. It can be seen that the variation in NPP over the year is greater in karst areas than non-karst areas (Figure 2b). This may be because karst areas with more croplands and grasslands have more obvious seasonal changes than non-karst areas spread with evergreen forests.

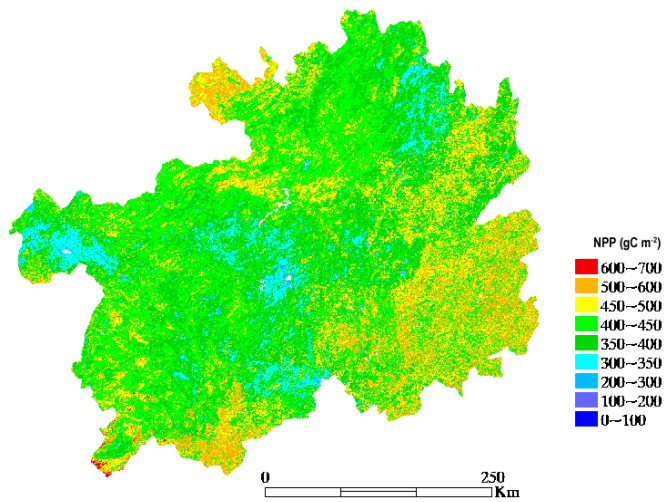

Figure 2a. Spatial distribution of NPP.

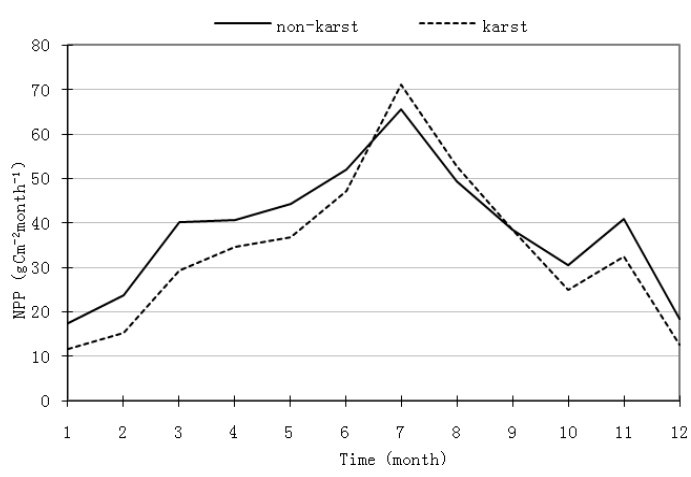

Figure 2b. Temporal variation of NPP in a year.

\subsection{Correlations between NPP and climate variables under current condition scenario}

Quantifying correlations between climate variables and NPP is of particular research interest. Vegetation yield in a certain region is determined by light, heat and water. Many early climate models, such as the Miami model (Lieth, 1972), the Thornthwaite model (Whittaker and Leith, 1976) and the Chikugo model (Uchijima and Seino, 1985), were based on climatic variables, such as temperature, rainfall and evapotranspiration. In this subsection, the correlations between NPP and temperature, and NPP and rainfall, are quantified using the single and partial correlation coefficients described in $§ 2.5$.

\section{Correlation between NPP and temperature}


The single correlation $\mathrm{R}$ values and partial correlation PR values show similar variation trends, decreasing from the north to the south.

The $\mathrm{R}$ values in most areas are above 0.8 , indicating that the correlation between NPP and temperature is relatively significant. Those areas with $\mathrm{R}$ values below 0.4 are in the southern and southeastern marginal counties. This may be because the temperature in these southern and southeastern marginal areas is relatively constant.

The PR values are generally slightly lower than the $\mathrm{R}$ values after removing the effects of rainfall (Figure 3a), indicating rainfall has certain effect on vegetation growth. It can also be observed that the PR values in karst areas are higher than in non-karst areas.

\section{Correlation between NPP and rainfall}

The fact that $\mathrm{R}$ values are above 0.6 in most areas implies that rainfall is also a significant factor in vegetation growth. Compared with other areas, the western counties tend to be wetter in summer and drier in winter due to higher altitudes, lower temperatures and less rainfall. Vegetation growth in these areas strongly depends on rainfall. The $\mathrm{R}$ values are accordingly above 0.8 in these areas. The $\mathrm{R}$ values below 0.4 are in the southern and southeastern marginal counties as for temperature. This could be because rainfall is not a constraint to vegetation growth in these counties due to sufficient moisture supply throughout the year.

The PR values decrease after removing the effect of temperature (Figure 3b), demonstrating that vegetation growth is impacted by both temperature and rainfall. However, there is a larger descending trend in NPP and rainfall than in NPP and temperature, indicating that temperature has the stronger influence on vegetation growth. The negative PR values (white in Figure $3 b$ ), ranging from -0.4 to -0.6 , indicate where vegetation growth is not restricted by moisture and has the strongest dependence on temperature. This may be due to hydrothermal asynchrony. In contrast to the correlation between NPP and temperature, PR values for NPP and rainfall in karst areas are somewhat lower than in non-karst areas.
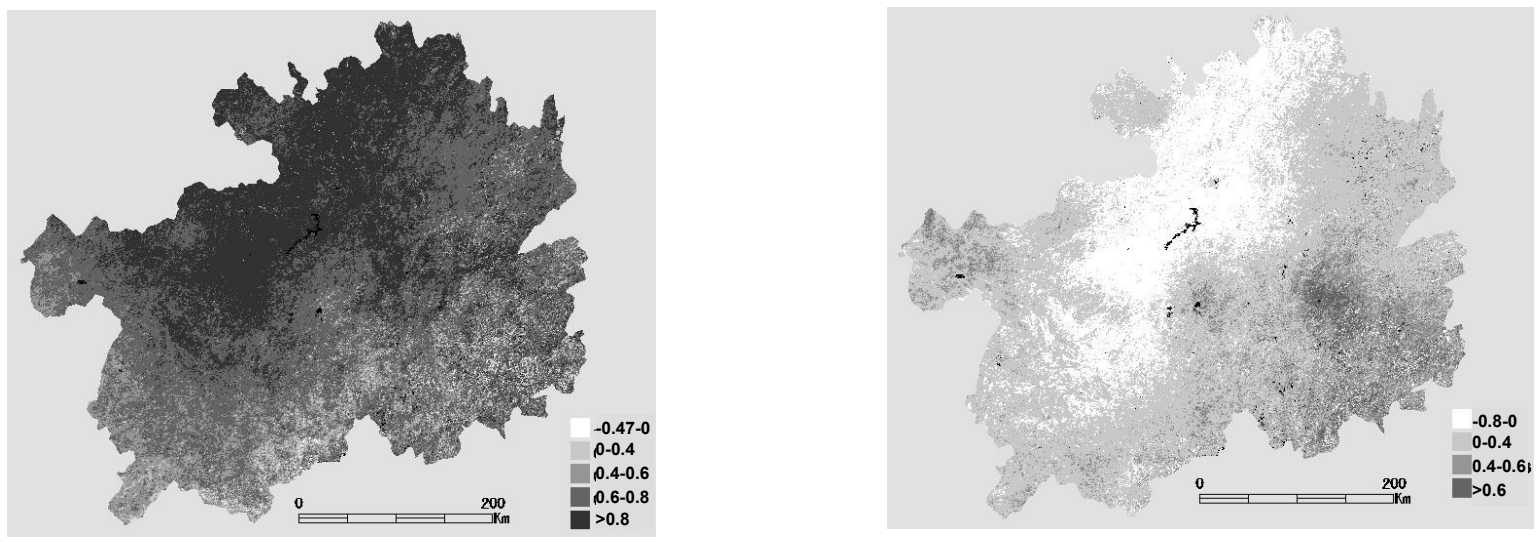

Figure 3. Partial correlation of (a) NPP and temperature and (b) NPP and rainfall.

\subsection{NPP response under future climate scenario one}

The negative values derived by subtracting NPP under current condition scenario from future scenario one in most areas, especially in the south, indicate a declining trend under this scenario (Figure 4a). Annual gross NPP decreases from $74 \times 10^{6} \mathrm{tC}$ to $73 \times 10^{6} \mathrm{tC}$; and mean annual NPP decreases from $421 \mathrm{gCm}^{-2}$ to $413 \mathrm{gCm}^{-2}$. This is a contrary to logical expectation that increased temperature and rainfall would result in an increase in NPP. This result points to the influence of other factors, such as evaporation and light stress effects. Counties with lower temperature and less rainfall tend to have an increase in NPP, indicating that temperature and moisture have a stronger (limiting) impact on vegetation growth in these areas. It can also be seen that the counties with an obvious decreasing trend are mainly in non-karst areas. The patterns of relative variation are similar to those of absolute variation, mostly $-3 \%$ to $+3 \%$ but below $-3 \%$ in the south (Figure $4 b$ ).

\subsection{NPP response under future climate scenario two}

Climate variables changes have greater impacts in karst areas than in non-karst areas under future scenario two (Figure 5a). NPP shows about a 7\% increase in the study area compared to under the current condition scenario, with annual gross NPP up to $79 \times 10^{6} \mathrm{tC}$ and mean annual NPP up to $452 \mathrm{gCm}^{-2}$. It can be seen that the obvious variation mainly appears in karst areas. The patterns of relative variation are similar to those of 
absolute variation (Figure $5 \mathrm{~b}$ ). It is lower in the south than the north, ranging between $5 \%$ and $10 \%$. The lowest values appear in southern non-karst counties, where the heat resources are most abundant with more rainfall and higher temperature. Therefore, the light energy is also one of the dominant factors affecting NPP in karst areas.

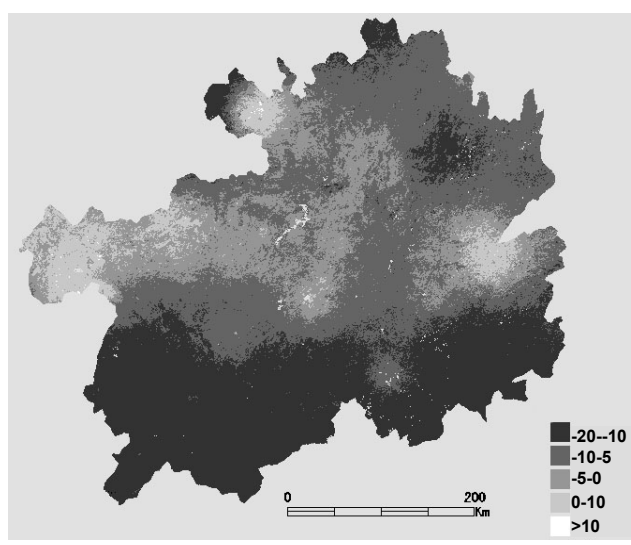

(a) Absolute variation $\left(\mathrm{gCm}^{-2}\right)$

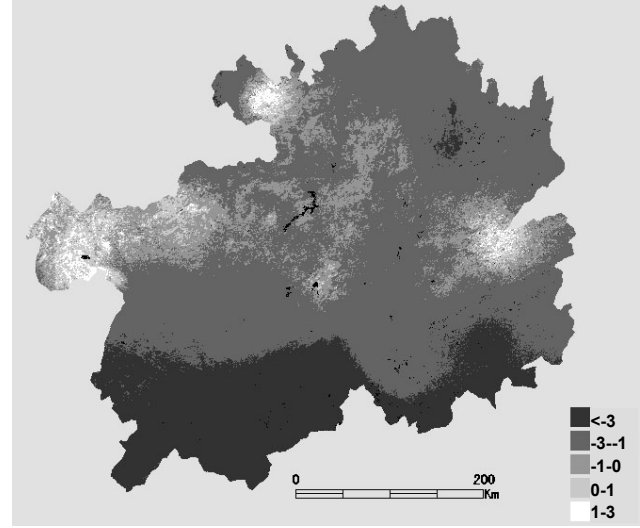

(b) Relative variation (\%)

Figure 4. Variation distributions of NPP under future climate scenario one.

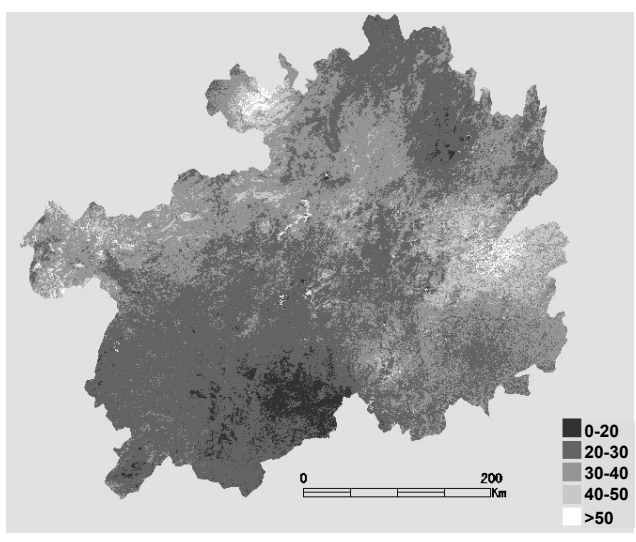

(a) Absolute variation $\left(\mathrm{gCm}^{-2}\right)$

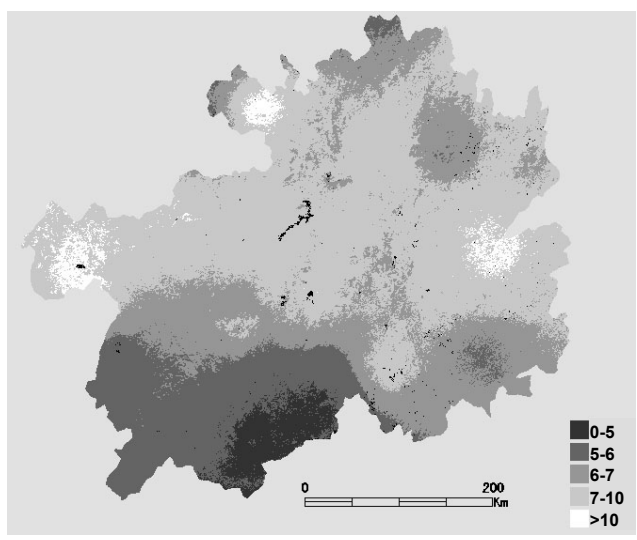

(b) Relative variation $(\%)$

Figure 5. Variation distributions of NPP under future climate scenario two.

\section{CONCLUSIONS}

Using MODIS imagery, climate data and observed radiation data, vegetation NPP in Guizhou province for the year 2001 was estimated. Under the current condition scenario, the mean annual NPP is $421 \mathrm{gCm}^{-2}$. NPP in karst areas is $11.9 \%$ lower than in non-karst areas. The maximum and minimum NPP values occur in July and January, respectively, and the largest variation being in the karst areas.

There are strong correlations between NPP and climate variables: (1) Temperature is a key factor which significantly limits vegetation growth in the northwest. The correlation between NPP and temperature decreases from north to south, and is stronger in karst than non-karst areas. (2) The correlation between NPP and rainfall is most significant in the southeast and west, and is lower in karst than non-karst areas. This indicates that both temperature and rainfall are key impact factors on NPP, and that temperature has the greater impact on NPP in karst areas.

Under the first future scenario, annual NPP decreases from $74 \times 10^{6} \mathrm{tC}$ to $73 \times 10^{6} \mathrm{tC}$; whereas under the second future scenario, annual NPP is up to $79 \times 10^{6} \mathrm{tC}$, an increase of $7 \%$ from current condition scenario. The results under both scenarios show that the larger increases in NPP mainly occur in karst areas, especially in areas with severe rock-desertification, and the light energy is also one of the dominant factors affecting NPP in karst areas.

This analysis of the interactions among three climate variables - temperature, rainfall and solar radiation has contributed to our understanding of their contributions to NPP, especially in karst areas. It has highlighted the 
Wang et al., Effect of climate variables on the modeling of vegetation net primary productivity in karst areas

probably significant role of evaporation and light stress effect and the need to extend the model to considering more factors in the further studies.

\section{ACKNOWLEDGEMENT}

This work was supported by the National Natural Science Foundation of China (No. 40671123) and National Basic Research Program of China (973) (2005CB422207) and was jointly undertaken by the Peking University and Beijing Normal University. Thanks to Susan Cuddy for kindly reviewing the manuscript.

\section{REFERENCES}

Cao M., Prince S.D., Li K., Tao B.O., Small J., Shao X. (2003). Response of terrestrial carbon uptake to climate interannual variability in China. Global Change Biology, 9(4), 536-546.

Cramer W., Kicklighter D.W., Bondeau A., Iii B.M., Churkina G., Nemry B., Ruimy A., Schloss A.L. (1999). Comparing global models of terrestrial net primary productivity (NPP): overview and key results. Global Change Biology, 5(S1), 1-15.

Fang J., Piao S., Field C.B., Pan Y., Guo Q., Zhou L., Peng C., Tao S. (2003). Increasing net primary production in China from 1982 to 1999. Frontiers in Ecology and the Environment, 1(6), 293-297.

Field C.B., Behrenfeld M.J., Randerson J.T., Falkowski P. (1998). Primary production of the biosphere: integrating terrestrial and oceanic components. Science, 281(5374), 237.

Gao Z.Q. and Liu J.Y. (2008). Simulation study of China's net primary production. Chinese Science Bulletin, 53(3), 434-443.

Goetz S.J. and Prince S.D. (1996). Remote sensing of net primary production in boreal forest stands. Agricultural and Forest Meteorology, 78(3), 149-179.

Keeling C.D., Chin J.F.S., Whorf T.P. (1996). Increased activity of northern vegetation inferred from atmospheric $\mathrm{CO}_{2}$ measurements. Nature, 382(6587), 146-149.

Lieth H. (1972). Modeling the productivity of the world. Nature \& Resources, 8(2), 5-10.

Lowry R. (2007). Concepts and applications of inferential statistics. Available: http://faculty.vassar.edu/lowry/webtext.html.

McNaughton S.J., Oesterheld M., Frank D.A., Williams K.J. (1989). Ecosystem-level patterns of primary productivity and herbivory in terrestrial habitats. Nature, 341(6238), 142-144.

Melillo J.M., McGuire A.D., Kicklighter D.W., Moore B., Vorosmarty C.J., Schloss A.L. (1993). Global climate change and terrestrial net primary production. Nature 363, 234-240.

Nemani R. R., Keeling C. D., Hashimoto H., Jolly W. M., Piper S. C., Tucker C. J., Myneni R. B., Running S. W. (2003). Climate-Driven Increases in Global Terrestrial Net Primary Production from 1982 to 1999. Science, 300(5625), 1560-1563.

Newbold, P.J. 1967. Methods for Estimating the Primary Production of Forests. IBP Handbook No.2. Blackwell, Oxford.

Prasad A.K., Chai L., Singh R.P., Kafatos M. (2006). Crop yield estimation model for Iowa using remote sensing and surface parameters. Int. J of Applied Earth Observation and Geoinformation, 8(1), 26.

Running S.W., Thornton P.E., Nemani R., Glassy J.M. (2000). Global terrestrial gross and net primary productivity from the Earth Observing System. Methods in Ecosystem Science, 44-57.

Seaquist J. W., Olsson L., Ardoe J. (2003). A remote sensing-based primary production model for grassland biomes. Ecological Modelling, 169(1), 131-155.

Sun R. and Zhu Q. (2001). Estimation of net primary productivity in China using remote sensing data. Journal of Geographical Sciences, 11(1), 14-23.

Uchijima Z. and Seino H. (1985). Agroclimatic evaluation of net primary productivity of natural vegetations (1) Chikugo model for evaluating net primary productivity. J of Agricultural Meteorology, 40(4), 343-352.

Wang B., Yang S., Lü C., Zhang J., Wang Y. (2010). Comparison of net primary productivity in karst and non-karst areas: a case study in Guizhou Province, China. Environmental Earth Sciences 59(6) 1337-1347.

Wen G., Yan Z., Ye D. (1997). Global Environment Change. Forecast and Research on the Trend of Environment Change in Future 20 to 50 Years in China. Changsha: Hunan Science and Technology Press, 1997.

Whittaker R. H. and Lieth H. (1976). Primary Productivity of the Biosphere, Springer-Verlag.

Xiong K. N., Li P., Zhou Z.F. (2002). Typical Study on Karst Rock-desertification using Remote Sensing and GIS-Taking Guizhou Province for Example, Geological Publishing House (in Chinese), Beijing. 